\title{
Musculoskeletal ProteinAnalysis Techniques - A Review
}

\author{
Srinath Kamineni ${ }^{1 *}$, Monica Manepally ${ }^{1}$, Ellora P Kamineni ${ }^{1}$ \\ ${ }^{1}$ Elbow Shoulder Research Centre, Department of Orthopedic and Sports Medicine, University of Kentucky, Lexington, KY, USA
}

Received: August 18, 2016; Accepted: September 12, 2016; Published: October 26, 2016

*Corresponding author: Srinath Kamineni Elbow Shoulder Research Centre, University of Kentucky, USA. E-mail: SrinathKamineni@gmail.com

\begin{abstract}
There have been a large number of experimental methods for purifying and analyzing proteins from the sample of interest. Determination of protein concentration is often the key step and is common to many applications in protein research and life sciences. The most commonly used quantitative techniques to measure the protein concentration are Amino acid analysis, Biuret assay, Bradford assays, Folin- Lowry assay, Bicinchoninic (BCA) assays, UV absorbance assays and Antibody-based assays such as ELISA and Western Blotting. Some of the qualitative methods that are used to detect different types of proteins and amino acids are Ninhydrin test, Xanthoproteic test, Millon's test, Sulfur test, Hopkins-Cole test, and Nitroprusside test. Chromatographic analysis can also be carried out on an either qualitative or quantitative basis to purify complex protein mixtures based on their properties such as size, solubility, charge, hydrophobicity and bio-specific interaction. Selection of these assays is based upon the ease of performance, range of concentrations, sensitivity, and interfering substances contained in the complex mixture. The purpose of this review is to provide an assessment of commonly used chromatographic and colorimetric methods for the determination of protein concentration.
\end{abstract}

\section{Introduction}

Proteins are macromolecules which are made up of along chain of amino acids. There are about 20 types of amino acids and each vary in size, polarity, shape, hydrophobicity and chemical reactivity and thus every single protein has different molecular structure with its own particular sequence and number of amino acids. The determination of protein concentration in a solution of interests an important aspect of analysis and has many applications in various clinical and research laboratories. The final success of research depends on choosing an appropriate essay by considering various factors, including the presence or absence of non-protein agents, the quantity of protein present in the sample and its composition which includes the content of amino acids. There are wide ranges of assays used to quantitatively and qualitatively assess the concentration of protein present in the sample. This article provides the review of the different methods of protein analysis, in current use.

\section{Methods of Protein estimation}

Quantitative protein analysis is an important tool in scientific research and development labs in order to understand the dynamics of a cell or other biological samples. The necessity for assessing the levels of particular proteins in samples is growing rapidly especially in the medical field to provide more specific diagnostic information. Some of the commonly used quantitative assays are UV absorbance assays, Colorimetric assays such as Biuret, Bradford, Folin-Lowry and Bicinchoninic (BCA) assays and Antibody-based assays such as ELISA and Western Blotting.

\section{Protein determination using Absorbance at $280 \mathrm{Nm}$}

Spectrophotometry is one of the most extensively used protein quantization assay that uses UV-Visible spectroscopy to access the concentration of protein in the sample. This method is advantageous dueto its simplicity, specificity, speed and low cost.

\section{Near UV Absorbance (280 Nm)}

A large number of bioanalytes can be detected by the absorption of ultraviolet radiation. Protein, including that in tissues, absorbs ultraviolet light quite strongly due to the presence of aromatic rings in the side chains of amino acids, tryptophan, tyrosine and phenylalanine. The absorbance of UV light is higher in tryptophan and tyrosine than phenylalanine and tryptophan is the only amino acid that absorbs UV at a maximum wave length between 275 and $280 \mathrm{~nm}$. But an absorbance of $260 \mathrm{~nm}$ is shown when the phenylalanine and disulfide bonds are formed between two cysteineresidues. UV absorption spectroscopy is relatively sensitive when compared to other methods and can measure protein concentrations as low as 10 $\mu \mathrm{gcm} 3$.It is a non-destructive technique as the protein sample can be recovered and reused further which is considered as one of the advantages. But the main disadvantage is the presence of chromospheres like nucleic acids that also absorbs UV light at $280 \mathrm{~nm}$ and affects the measurement of protein concentration, but this difficulty is overcome by quantification (measurement of absorbance) at two different wavelengths. From this technique, protein concentration is easily calculated by knowing the molar absorptive and measured absorbance of the sample solution at $280 \mathrm{~nm}$. Also a calibration curve that is plotted from several known amounts of protein can be used for comparison in order to assess the unknown protein concentration[1]. 


\section{Far UV Absorbance}

The concentration of the proteins that lack aromatic amino acids and disulfide linkage can be assessed using "far UV absorption" as they do not absorb near UV radiation. The major chromospheres in this spectral region are the peptide bond with a wavelength ranging from $190 \mathrm{~nm}$ to $220 \mathrm{~nm}$, whereas in the nearUV spectral region aromatic residues and disulfide bonds are the main chromospheres. But at $190 \mathrm{~nm}$, oxygen strongly absorbs UV light, thereby reducing the light available for measurement and also the output of deuterium arc sources is low at this particular wavelength. Hence it is convenient to measure the absorption at a wavelength of $205 \mathrm{~nm}$ in far UV region and the protein concentration can be measured to less than $1 \mu \mathrm{g} \mathrm{cm}-3$. The only difficulty while working at these lower wavelengths is the absorbance of UV light by the buffer and additional components [2].

\section{Colorimetric Assays}

\section{Biuret Method}

One of the simplest and the most common assays the Biuret Protein assay. The main principle of this assay is under alkaline conditions, cupric ion complexes with the adjacent peptide bonds in protein and forms an intense purple color complex. This reaction arises only with the presence of peptide bonds and not with amino acid side chains. The maximum intensity of the color is attained after fifteen minutes and the formed complex remains stable for several hours. The intensity of the color is directly proportional to the protein concentration, which is measured spectrophotometrically at $540 \mathrm{~nm}$ [3]. This method requires a large amount of sample as it measures those protein concentrations ranging from 0.5 toapproximately $5 \mathrm{mg} / \mathrm{ml}$. Very few materials (e.g. Tris and amino acid buffers) interfere with this assay, which is considered as one of its advantages and the only disadvantage is its low sensitivity [4].

Zaia et al.[5] tested biuret, Lowry/ Hartree, $P$-chloranil, UV$280 \mathrm{~nm}$, and UV-260/280 $\mathrm{nm}$ for the estimation of total proteins in seven rat tissues adrenal, spleen, whole brain, small intestine, pancreas, liver and epididymal fat pad. The sensitivity of Lowry/ Hartree reaction was high for the proteins and comparatively low for Biuret reaction. However, a good correlation was noticed between the results of these two assays. As Lowry/hartree assay was more of time-consuming, the authors suggested the biuret method for five tissues adrenal, spleen, whole brain, liver, small intestine and UV-260/280 nm for whole brain, liver, and pancreas and p-chloranil assay for epididymal fat pad. In another study by Jenzano et al.[6], the accuracy of biuret, Lowry, BCA, $\mathrm{CB}$ assay in either phosphoric acid formulation [7] or in $\mathrm{HCI}$ formulation proposed by Sedmak and Sidney [8], were evaluated for the assay of protein concentration in human mixed saliva. The data of amino acid analysis results were compared with the values of the colorimetric assays. With BSA as the standard, the concentrations determined by the Biuret assay were more accurate to those obtained by AAA. Due to the presence of very few aromatic amino acids low values were obtained with the Lowry method. Dawnay et al. [9] have surveyed 5 methods and concluded biuret assay as a simple, rapid and suitable method for the assay of serum proteins. Sapan et al. [4] recommended using Biuret assay, quantitative amino acid analysis and microKjeldahl technique, when the amount of unknown protein in the sample does not match the standard. Since the early 1980s, biuret was the most commonly employed technique, but its only disadvantage is the lack of sensitivity for detecting the proteins which are in small volume of samples.

\section{Bradford (Bio-Rad) Method}

Bradford assay is a dye-based assay used to measure the protein content in cell fractions. It measures protein concentrations ranging from 10 and $100 \mu \mathrm{g} / \mathrm{ml}$. This assay relies on the change in the spectral shift from $465 \mathrm{~nm}$ to $595 \mathrm{~nm}$, due to the strong binding of negatively charged Coomassie Brilliant Blue (CBB)G-250 dye to hydrophilic arginine and hydrophobic amino acid residues in the protein sample under acidic conditions that result in the formation of a blue color complex. The intensity of the color complex depends upon the concentration of the protein which can be measured at $595 \mathrm{~nm}$. This colorimetric assay is more rapid and compatible with most of the buffers, salts and solvent sand less prone to interference by various compounds that are present in protein samples [7].

In one of the studies, Dilena et al.[10] compared the linearity, precision, comparative bias, and practicability of the coomassie brilliant blue technique of Heick et al. [11], biuret technique [11], trichloroacetic acid turbidimetry [12], and Ponceau-S dye binding [13], for urinary protein determination and the results reported low precision and linear range for CBB assay. And comparatively biuret technique had better precision and linear range, but required an undesirably large volume of sample. In another study by Swain et al.[14], the accuracy of two dye-binding procedures, Cellulose-Dye (CD) and the Coomassie Brilliant Blue (CBB) were compared with a Gel Filtration/modified Biuret method (GFB) for measurement of total protein in the urine. Indistinguishable results were obtained for the three assays for the urine sample containing high protein concentrations, whereas lower values were obtained for the two dye binding assays than the GFB method when normal protein samples were analyzed.

Hence, although the standard Bradford technique was very sensitive and accurate, there were difficulties associated with the identification of immunoglobulin light chain urinary proteins and cerebrospinal fluid proteins for clinical laboratory analysis. Macart et al.[15] approached this problem by adding Sodium Dodecyl Sulfate (SDS) to the sample prior to the addition of Comassie Brilliant Blue (CBB) reagent and concluded that the modified method provides equal reactivity to human albumin, IgG and transferring. Wimsatt et al.[16] applied the latter to urinary proteins and also determined it as a simple and appropriate method. Perini et al.[17] compared the CBB (Bradford) method and the CBB-SDS method for urinary protein determination and recommended using the CBB-SDS assay.

On the other hand, the original Bradford method was also not suitable for the estimation of proteins in collagen rich samples. Duhamel et al.[18] found out that inclusion of SDS in the dye 
binding assay induces a 4-fold increase in the color response of three collagen proteins (Col I, III and IV) and decrease in the color yield for other non-collagen proteins. Lopez et al. [19]also concluded that this modification of Bradford assay minimizes the large variations of response between collagen and noncollagen proteins. In a Bradford-micro assay procedure, Pande et al.[20] have reported that co-precipitating proteins with calcium phosphate in an ethanolic medium before the addition of dye reagent eliminates interfering substances and detergents.

\section{Bicinchoninc Acid (BCA) Assay}

BCA assay is a copper-based colorimetric assay which depends on biuret reaction where the proteins back bone chelatescupric ions and reduces them to cuprous ions under alkaline conditions. When the seions react with the organic dye, bicinchoninic acid, an intense purple-colored product is formed which can be measured spectrophotometricallyat $562 \mathrm{~nm}$, against a standard curve of absorbance from varying Bovine Serum Albumin (BSA). The incubation temperature determines the rate of color formation in BCA assay and its unique advantage over the other assays is its compatibility with samples containing up to $5 \%$ detergents and denaturants. But, due to its sensitivity to the presence of reducing sugars in the buffer that interfere with the dye, few reducing agent-compatible dyes are available. It can measure protein concentrations rangingfrom $0.5 \mu \mathrm{g} / \mathrm{mL}$ to $1.5 \mathrm{mg} / \mathrm{mL}$ [21].

The Amino Acid Analysis (AAA) research group Alterman et al.[22] compared the quantization of range of proteins by AAA with the BCA, Bradford and Lowry assays. The reports indicated that only the values obtained with the BCA assay were consistent with AAA than both the BCA and Lowry assays. Keller and Nellville[23] have examined the BCA, Biuret, Bio-Rad Coomassie Blue and Pierce BCA methods for the assay of total protein in human milk. Though there was a good correlation between the values obtained from the colorimetric assays with the standard micro-Kjehdahl method, only BCA assay displayed the greatest accuracy and consistency. In another study, Fountoulakis et al.[24] compared the BCA, Lowry and CB methods to analyze the glycosylated and non-glycosylated proteins. For the glycosylated proteins, the values obtained with those three colorimetric assays have not displayed significant correlation with the standard amino acid analysis, but for the non-glycosylated proteins, the concentrations determined by BCA assay only were accurate.

\section{Folin-Lowry Method}

Lowry assay is based on both the biuret reaction and FolinCiocalteau reaction and is considered as one of the most accurate method in determining protein concentration. It can measure protein concentrations ranging from $0.01-1.0 \mathrm{mg} / \mathrm{mL}$ in a sample. By mixing the protein sample with copper sulphate solution and Folin reagent (a mixture of sodium Tung state, molybdate and phosphate) under alkaline conditions, peptide bonds react with copper and produces cuprous ions. The reaction further involves the reduction of Folin reagent and oxidation of aromatic amino acid residues, tyrosine and tryptophan. The end product of this reaction is the formation of blue-purple color which can be quantified by reading the absorbance at a wavelength of $750 \mathrm{~nm}$ against a standard calibration curve of Bovine Serum Albumin protein solution. This assay is more susceptible to interference by arrange of substances, including buffers, drugs, nucleic acids, and sugars. As the amount of the colored product depends upon the content of tryptophan and tyrosine residues in the protein, higher absorbance values are observed in those proteins that comprise large mole fractions of amino acid residues. In order to estimate the absolute value for protein concentration in this assay, the protein being assayed should also be used to construct the calibration curve [25]. Despite its recognition in various studies, there were also many problems as cited above $[5,8]$ with the traditional Lowry assay, such as susceptibility to various interfering substances, reagent instability and also requires high time to develop color. However, with the advance of more accurate and sensitive assays, the use of Lowry assay has reduced in recent years.

\section{Qualitative Tests}

Amino acids react with reagents and can be identified in a sample solution as they exhibit typical color reactions due to the presence of specific characteristics defined by their unique side chains for each of them and also it is the side chain that dictates the chemical properties of amino acids. The most commonly used qualitative methods to detect different types of proteins and amino acids are described below.

\section{Ninhydrin Test}

Ninhydrin is a strong oxidizing agent used in amino acid analysis for the precise determination of protein quantities. It is mainly used as a detector in liquid chromatography methods coupled with ninhydrin post-column derivatization systems. The reagent which is initially yellow reacts with free alpha amino groups present in all amino acids, proteins, or peptides and forms a deep blue or purple colored complex known as Ruhemann's purple. Its absorb an ceis measured at $570 \mathrm{~nm}$ using aspectrophotometer[26].

\section{Xanthoproteic Test}

The Xanthoproteic test uses a nitration reaction to determine the presence of proteins in a solution. When the sample is treated with a hot, concentrated nitric acid it reacts with aromatic amino acids such as phenylalanine, tyrosine and tryptophan and forms a yellow colored product known as Xantho protein. With the addition of strong base such as $\mathrm{NH} 3$ or $\mathrm{NaOH}$, it further changes to deep-orange color. So this test gives a positive result in those proteins which contain amino acids that have aromatic rings in their side chains[27].

\section{Millon's Test}

Millons reagent is the solution containing mercuric nitrate that is dissolved in nitric acid and is used to identify the presence of phenolicamino acids such as tyrosine and its derivatives. By mixing the sample with this reagent and heating it gently results in the formation of reddish-brown color precipitate signaling the presence of tyrosine. Some of the proteins containing aphenolic hydroxyl group initially form a white precipitate and changes to 
red when heated which is also considered as a positive result[28].

\section{Sulfur test}

Sulfur-containing amino acids such as cystine, cystine and methionine respond to this test. By boiling the sample with $\mathrm{NaOH}$, organic sulfur in these amino acids partially convert to inorganic sulfide and produce sodium sulfide. This reaction can be further detected by combining the sulfide solution with lead acetate. The formation of black or gray precipitate of $\mathrm{PbS}$ (lead(II)sulfide) is considered as a positive test for sulfur-containing amino acids[29].

\section{Hopkins-Cole Test}

This chemical test is used to identify the presence of tryptophan, the only amino acid containing in dole group. When the protein solution is mixed with Hopkins- cole reagent the in dole ring reacts with the glyoxylic acid in the presence of concentrated sulfuric acid and forms a violet or purple colored product, signifying a positive result[27].

\section{Nitroprusside Test}

This test is used to detect the presence of sulfur containing amino acid, cysteine in a protein. When the sulfhydorxyl group reacts with sodium nitroprus side in alkaline solution, it yields a red colored product indicating a positive result of the presence of amino acid cysteine[30].

\section{Amino Acid Analysis}

Amino acid analysis is an appropriate tool for accurate determination of protein concentrations. It provides complete information about the relative amino acid composition, including free amino acids that are often well enough to identify of proteins. The analysis procedure involves protein hydrolysis in the first step and separation, detection and quantification by HPLC analysis in the second step. Acid hydrolysis, which can be used in both liquid and gas phase mode is the most frequent method used to hydrolyze a protein sample into its individual amino acid components. The sample can be dried in a vacuum after hydrolysis and is dissolved in loading buffer. But this technique can have varying effects on sensitive amino acids like tryptophan, serine, threonine, methionine, cysteine[29].To reduce losses during hydrolysis, several investigations were done to use different protective agents such as phenol, in dole, thioglycolic acid and alternative non-oxidizing agents such as $4 \mathrm{M}$ methanesulfonic acid. Also, the introduction of microwave radiation energy for hydrolysis of protein samples allows the hydrolysis time reduction from many hours to few minutes[31].

In the second step of analysis, the liberated amino acids are separated by ion-exchange chromatography. It is coupled with ninhydrin or o-phthalaldehyde post-column derivatization system which can measure from $5 \mu$ gto $10 \mu \mathrm{g}$ of protein sample per analysis and can be used with samples comprising small amounts of sodium or lithium buffer components. Also ReversedPhase High Performance Liquid Chromatographic (RP-HPLC) technique can be used for separation of amino-acids with online pre-column Ortho-Phthalaldehyde (OPA) derivatisation and fluorescence detection providing higher sensitivity to the system[32]. Amino acid analysis, as cited above [8, 22, 24], still remains the "golden standard technique" for absolute protein and peptide quantification in various scientific studies.

\section{Antibody-Based Assays}

\section{Elisa}

ELISA is the most sensitive and simple biochemical technique used for qualitative and quantitative determination of proteins secreted from cells. There are two main types of ELISA that can detect and quantify antigen or anti body concentrations: Direct ELISA and indirect ELISA. The indirect sandwich assay is a best choice to detect a protein with multiple epitopes. It is a sensitive assay which measures the antigen concentration between two layers of antibodies. In this rapid test, an unknown amount of antigen is immobilized onto a polystyrene surface which acts as a solid phase and then a specific antibody which is diluted in blocking buffer is coated over the surface that binds to the antigen. An enzyme linked antibody molecule is also added which is allowed to bind to the immobilized antigen. In the final step a chromogenic substrate for the enzyme is added to the antigen/ antibody/enzyme complex and causes color to develop. The intensity of color developed is directly proportional to the concentration of bound antibodies and can be measured with a spectrophotometer [33]. The stages of direct ELISA are similar to indirect ELISA, but in direct format the enzyme conjugated anti body is directly added and a substrate for this enzyme is added which changes color upon detection of the enzyme [34]. Topping et al. [35] devised an enzyme-linked immunosorbent assay to measure the urinary Retinol-Binding Protein (RBP) for the detection of Tubular Proteinuria. In another study, Lucertini et al. [36] detected RBP proteins in human serum and urine by using a double-antibody "sandwich"-type enzyme-linked immunosorbent assay. In both the studies, the results correlated well when compared with the latex immunoassay, suggesting ELISA as a simple, sensitive and an alternative method for the measurement of tubular function.

\section{Western Blotting}

The western blotting technique which is also known as immune blotting, is a powerful tool used for the qualitative and semi-quantitative determination of a particular protein in a complex mixture. In principle, the method allows the separation of proteins according to their size via gel electrophoresis and identification of the target protein using specific antibodies. After the protein separations they are electrophoretically transferred from SDS-gel onto nitrocellulose or Polyvinylidene Fluoride (PVDF) membrane and probed with approximately matched anti bodies that detect the target protein. Then a secondary anti body conjugated to a reporter enzyme or fluorescent dye is added to bind to the primary anti body and produces a color proportional to the concentration of protein. The most sensitive detection methods use secondary anti bodies which are linked to two enzymes Alkaline Phosphates(AP) and Horseradish Peroxidase (HRP) that produce a colored precipitate on the membrane for colorimetric or fluorometric detection[37]. Hossenlopp et al. [38] 
used the western blotting technique to detect Insulin-like Growth Factor (IGF) binding proteins in normal and hypo pituitary human serum and the isolated binding proteins were further measured by titration assay.

\section{Detection and estimation of proteins Ingles}

\section{Two Dimensional Gel Electrophoresis}

2-DE is one of the widely used methods to classify a large number of proteins in complex mixtures based on two independent properties in two dimensions in 2D gels. In the first dimension, proteins are separated based on an isoelectric point (pI) and this method is known as isoelectric focusing. When the sample is placed on the gel with a $\mathrm{pH}$ gradient, protein based on their charges migrate along the $\mathrm{pH}$ gradient in the presence of an electric field. They move up to a certain point in the gel where their pI equals to the $\mathrm{pH}$. Immobilized pH Gradient (IPG) gel strips can be used toper form IEF technique which can later be used in second dimension separation technique, SDS-PAGE, where the proteins are classified based on their Molecular Weights (MW). Sodium Dodecyl Sulfate (SDS), which is an anionic detergent, is typically added to coat the proteins with a uniform negative charge. As it binds uniformly to all the proteins, they have similar charge-to-mass ratios and similar shapes. Now based on their molecular weight SDS- treated proteins will migrate towards the anode when placed in an electric field. SDS-PAGE is highly used to test the purity of proteins during chromatographic or other purification procedures.

To visualize the separated proteins in the gel, the most commonly used staining methods are silver staining, Coomassie brilliant blue dye stain and fluorescent staining[39]. In silver staining, the silver colloid is deposited onto the surface of the gel which binds to certain functional groups of proteins. On exposure to ultra-violet light, the silver gets darkened. The amount of silver can be related to the darkness, and therefore the concentration of protein at a given position on the gel. The separated proteins after staining can be recognized using Liquid ChromatographyMass Spectrometry (LC-MS). The protein band that is cut from the gel issolubilized and digested into peptide fragments using a protease enzyme which is mostly trypsin. The short peptide fragments are then isolated by liquid chromatography and subjected to MS/MS analysis to further sequence them.

MS is an analytical tool used to detect and identify and provide quantitative information of the proteins in a manner conceptually similar to Edman degradation. "Tandem Mass Spectrometry (MS/ MS)"analysis consists of two stages, where in the first approach, fragments are ionized by the ion source electro spray ionization (ESI) or Matrix Assisted Laser Desorption Ionization (MALDI). Then the mass analyzer separates the charged, gas-phase ions using an electrical and/or magnetic field and selects the peptide ions based on their mass and charge (MS1). In the second stage, the precursor ions are striked with neutral gas molecules in the collision cell of the mass spectrometer. They are fragmented into smaller pieces and separated again based on their $\mathrm{m} / \mathrm{z}$ ratios and intensities (M/S 2). The fragmentation pattern programmed by the tandem spectrum allows the identification of peptide sequence and compared with a predicted MS spectrum that can be found in the protein sequence databases such as IPI, SEQUEST, Mascot and Swis-Prot [40]. Most of the chromatographic techniques are coupled with mass spectrometry due to the high sensitivity and specificity of its detectors [41].

Manabe et al.[42] used the 2-DE technique in the absence of denaturing agents to separate and analyze the native human plasma proteins, in which isoelectric focusing was used in the first dimension, followed by electrophoresis in a 4-21\% linear gradient slab gel in the second dimension. In another study, Dale et al. [43] have described a technique to separate blood serum proteins by employing isoelectric focusing in an acrylamide gel in the first dimension followed by electrophoresis in the same medium. The authors have also suggested using this technique on CSF and urinary proteins. Chatterji et al.[44] applied 2-DE technique to extract the serum proteins from a tumor bearing mice and detected around 46 proteins by analyzing them using MALDI-TOF/TOF. Li et al.[45] compared five proteomic methods, 2-DE-MALDI-TOF-MS/MS, 2-D HPLC followed by tryptic digestion of each fraction and micro capillary RP-ESI-MS/MS , On-line and Off-line 2-D HPLC with micro ESI-MS/MS, 2-D HPLC followed by optimizing the fractions with nano RP-HPLC-nano ESI-MS/MS to characterize the human serum proteins. Their results reported the identification of 37 proteins by all five approaches, but only 2-DE method provided more data on pI-altered isoforms of the proteins in the serum and also estimated the relative abundance of identified proteins.

\section{Chromatographic Analysis}

Chromatography refers to a set of techniques used to purify complex protein mixtures based on their properties such as size, solubility, charge, hydrophobicity and bio-specific interaction. Chromatographic analysis can be carried out on an either qualitative or quantitative basis. Qualitative analysis confirms the presence of a specific protein in a test sample by relating the retention time of the peaks in the chromatograph with that of a reference sample of the test protein obtained under identical chromatographic conditions. Quantification of a given analytics also based on the construction of a calibration curve. The area of each peak in a chromatogram is obtained by the product of the Height of the Peak (HP) and Width at half the Height (WH) and is proportional to the amount of the analyte producing the peak. As this procedure is time consuming, these can be programmed to compute retention time and peak area and relate them to standard references[46].

\section{High-Performance liquid Chromatography (HPCL)}

HPLC is a form of column chromatography used to analyze proteins based on size, charge or over all hydrophobicity. The sample is dissolved in a small volume of liquid and forced with a high pressure pump into the column tube. This column which acts as a stationary phase is packed with tiny particles of chromatographic material that effects the separation. The physical and chemical interactions between the mobile phase and stationary phase lead to the separation of components. As they elute from the column, they reach the detector that measures their 
amount and provides an output called as "liquid chromatogram". The most commonly used detectors are variable wavelength detectors, fluorescence detectors, mass spectrometer detectors, NMR detectors and refractive index detectors[47].

Fast Protein Liquid Chromatography (FPLC) is alike HPLC in principle, but the only difference between them is the amount of working pressure applied by the pumps to the column. FPLC columns can only be used up to maximum pressure of 3-5 $\mathrm{MPa}$ (435-580 psi) and in HPLC, the pressurized pump generates pressure of $0-550$ bar (14.6-8000psi). But the advantage of the HPLC system is that it can use both the columns whereas FPLC works only with the FPLC column [48].And systems that operate at pressures $<50$ psi $(\sim 3$ bar $)$ are characterized as Low Pressure Chromatography (LPLC) systems and are often used for simple protein separations that do not require high resolution. Larger particle size phases form the basis of low-pressure liquid chromatography in which the flow of eluent through the column is either gravity-fed or pumped by a low pressure pump, often a peristaltic pump. This technique separates proteins through a bed of porous beads where the molecules are eluted off the column in order of decreasing size [49].

Proteins are fractionated from the cell lysate by using different types of HPLC columns such as size exclusion, affinity, ion exchange, ligand-exchange, reversed-phase, normal phase. Separation mechanisms are chosen according to the size, binding affinity, polarity, hydrophobicity of bio molecules. As HPLC techniques are classified into various types according to the nature of stationary phase, few of the most commonly used chromatography approaches are reviewed here. Coupling MS with multidimensional electrophoretic and HPLC techniques enables the characterization of complex protein mixtures with high resolution.

\section{Reversed Phase-High Performance Liquid Chromatography (RP- HPLC)}

Segregation ofmoleculesdependingupontheir hydrophobicity for closely identical sequences of polypeptides of a wide range, from small peptides obtained through trypsin digestion to large proteins is possible through RP-HPLC. This technique is often used because of its high productivity and resolution among close related molecules along with good eproducibility of separations done over longer periods of time. By changing the mobile phase characteristics, chromatographic selectivity can be obtained. The separation depends on the hydrophobic binding of the solute molecule and the immobilized hydrophobic ligands where proteins carry both hydrophilic and hydrophobic amino acids. When the mixtures of proteins pass through the column, polar proteins elute first followed by less polar and the remaining nonpolar proteins bind to the column. Elution of bound hydrophobic protein is facilitated by enhancing the concentration of organic solvent, thereby increasing the retention time. Reverse phase chromatography as cited in $[55,57,58]$ is usually done alongside mass spectrometry in a way to analyze the protein that is eluted from the column[50].Wall et al.[51] described a two-dimensional liquid-phase separation method coupled with a MALDI-TOF mass spectrometer to separate and profile the cellular proteins, by using isoelectric focusing in the first dimension and RP-HPLC in the second dimension and the selected fractions were analyzed using MALDI-TOF MS. By using this technique, the authors were able to resolve 700 protein bands with a high resolution and substantiated this approach as an alternative to 2-D gel separation technique.

\section{Two-Dimensional Nano high -Performance liquid Chromatography}

For better separation and hydrophobic peptide recovery, 2D nano HPLC is used, specifically for complex peptides made from enzymatic digests of selected proteomes. The peptides are separated by their electric charge state and distribution through elution of the digested peptides from the Strong Cation Exchange (SCX) column with injected salt solution plugs of increasing concentration. After which the eluted peptides are trapped and introduced into RP nano flow path for separation to be done based on hydrophobicity and are pre-concentrated before introducing them to MS/MS analysis. The procedure is continued until all peptide fragments are eluted and analyzed [52]. Using the combination of SDS-PAGE assay and two-dimensional nano liquid chromatography (2D-nano LC) coupled online with tandem mass spectrometry, the membrane proteins from mouse brain tissues were detected and categorized in a research study led by Van Chi and Nguyen Tien Dung [53]. In another study, Choi et al. [54] compared two methods, 2-DE coupled to MALDI-TOF-MS and ESI-MS/MS analysis (2DE-MS) and the on-line 2D nano LC, followed by nano ESI-MS/MS analysis (2DLC-MS) to identify and characterize the proteins depleted from human plasma. Though both the techniques identified a unique set of proteins, 2DLCMS assay was more advantageous as it assessed the proteins in a high-throughput manner.

\section{Affinity Chromatography}

Affinity chromatsography takes the advantage of unique biological features of proteins to achieve separation and purification based on specific protein-ligand interactions. But this method requires that a detailed underlying characteristics of the structure and biological specificity of the compound in consideration to be known in order to achieve separation conditions. As the protein solution is added, the ligands immobilized on the column such as antibodies, receptors, ligands, or specific binding partners bind specifically to the component to be purified from the mixture. Mass spectrometry is then carried out on the eluted protein from the column after it is washed thoroughly to remove any non-specific bound proteins [55].

Reactive dyes in the column are also used in affinity chromatography to separate and purify a wide variety of proteins in a selective and reversible mode. Travis et al. [56] discovered the ability of sepharose blue dextran conjugate to bind the proteins of serum or plasma albumin in the column and the results showed $96 \%$ of albumin adsorption to the SBD column. Thomas and his coworkers adapted a similar approach for the separation of albumin proteins from the blood plasma of four species; rats, guinea pigs, baboons and humans and reported 
highest percentage of recovery of serum albumin in human and baboon than guinea pig or rat. Bécamel et al.[57] discovered a sensitive method to identify the interaction of multi protein complexes with intracellular domains of membrane-bound receptor (G-protein coupled receptors), by using peptide affinity chromatography to purify the proteins. The eluted proteins from the column were resolved on a high resolution 2-D gel and stained with silver and further analyzed by MALDI-TOF mass spectrometry. Also immunoblotting was combined along with MS in order to detect low amounts of protein components.

\section{Ion Exchange Chromatography}

The net charge on proteins at a particular $\mathrm{pH}$ varies due to variations in the contents of charge damino acids .Ion exchange chromatography is based on the reversible adsorptiondesorption of ions in solution on a charged solid matrix or polymer network. A positively charged and a negatively charged matrix bind to anions and cations and are called anion-exchanger and cation-exchanger respectively. Chemical modifications of the matrix such as weak or strongly acidic and weak or strong basic is possible since weakly acidic groups behave as cation exchanger, and that with a weakly basic group behave as anion exchanger which are appropriate for separation and purification of most proteins. To ensure good bonding of protein to the ion exchange column, the PH and ionic strength of elution buffer are optimized. Contaminated proteins bind less strongly and hence pass quickly through the column. Finally, by changing the buffer solution to a different $\mathrm{pH}$ and ionic strength which will favor desorption from the column in order to elute it[46].For many protein purifications, such as albumin and IgG, ion exchange column chromatography matrices are employed. Strong Cation Exchange chromatography (SCX) followed by RP-HPLC is one of the most widely used separation technique to identify simple and complex mixture of peptides. Han et al.[58] described a 2-D separation technique to characterize the proteins present in microsomal fractions of naïve and in vitro-differentiated human myeloid leukemia (HL-60) cells, using SCX followed by RP-HPLC coupled with a micro capillary liquid chromatography-electrospray ionizationtandem mass spectrometry ( $\mu$ LC-ESI-MS/MS).

\section{Sizes-Exclusion Chromatography (Sec)}

Also known as gel filtration chromatography as the name suggests, works by segregating proteins based on their molecular size by determining their molecular weights and weight distributions. The main advantage of this method is its ability to maintain the native structure and function of the purified protein since a large variety of buffers can be used to obtain the desirable condition for the protein. This method works by adding a protein solution into a stationary column packed with porousdextran or agarosehydrophilicgel beads. When the protein passes through the gel beads, the smaller molecules which can enter the pores are slowed down whereas the bigger molecules which cannot enter the beads, slide and move around the beads there by rapidly passing through the column. Thus, molecules are eluted off the column in order of decreasing size by varying the average pore size of the beads which are available for a wide range of molecular masses. The eluent is collected in fractions and later analyzed by spectroscopic techniques [59].

In one of the studies, Opiteck et al.[60]identified the proteins from a bacterial cell lysate by employing the 2-D HPLC system, where the proteins are separated using size-exclusion chromatography (SEC) in the first dimension, and analyzed by RP-HPLC based on their hydrophobicity in the second dimension. The fractions selected from RP-HPLC column were then resolved by MALDI-TOF/MS or ESI/MS. Also in another study, Opiteck et al. [61] applied 2-D SEC/RPLC method coupled to electrosprayMS to analyze a mixture of peptide fragments resulting from the digestion of a protein. Owen et al.[62] compared size exclusion high-performance liquid chromatography (SEC-HPLC) with an automated Immune Turbidimetric Assay (ITA) to evaluate the amount of micro albuminuria (urinary protein). In these studies, the results indicated that HPLC gave albumin concentration nearly 4 times greater than those obtained by immunoassay, which clearly suggests that SEC-HPLC is an appropriate method to estimate the albumin proteins that are not detected by ITA.

\section{Conclusion}

Protein is an indicator of biological entity or activity. As many of the medical conditions are associated with protein malfunction, there is a need to isolate pure proteins and explore various aspects of its structure and functions in order to design diagnostic and the rapeutic tools for disease control. Hence protein analysis is highly required in many research and clinical laboratories.

\section{References}

1. Schmid F. Encyclopedia of life sciences, in Biological Macromolecules: UV-visible Spectrophotometry. 2001; John Wiley \& Sons, Ltd.

2. Scopes RK. Measurement of protein by spectrophotometry at $205 \mathrm{~nm}$. Analytical biochemistry. 1974;59(1):277-282.

3. Switzer R, Garrity L. Experimental biochemistry: theory and exercises in fundamental methods. 1999; WH Freeman and Company, New York.

4. Sapan CV, Lundblad RL, Price NC. Colorimetric protein assay techniques. Biotechnology and applied Biochemistry. 1999;29(2):99108.

5. Zaia DAM, Verri Jr WA, Zaia CTBV. Determination of total proteins in several tissues of rat: a comparative study among spectrophotometric methods. Microchemical Journal. 2000;64(3):235-239.

6. Jenzano JW, Susan L Hogan, Claudia M Noyes, Gerald L Featherstone, Roger L Lundblad. Comparison of five techniques for the determination of protein content in mixed human saliva. Analytical biochemistry. 1986;159(2):370-376. doi:10.1016/00032697(86)90355-6.

7. Bradford MM. A rapid and sensitive method for the quantitation of microgram quantities of protein utilizing the principle of protein-dye binding. Analytical biochemistry. 1976;72(1):248-254.

8. Sedmak JJ, Grossberg SE. A rapid, sensitive, and versatile assay for protein using Coomassie brilliant blue G250. Analytical biochemistry, 1977;79(1):544-552.

9. Dawnay A, Hirst AD, Perry DE, Chambers RE. A critical assessment of current analytical methods for the routine assay of serum total 
protein and recommendations for their improvement. Annals of clinical biochemistry. 1991;28:556-557.

10. Dilena B, Penberthy LA, Fraser CG. Six methods for determining urinary protein compared. Clinical chemistry. 1983;29(3):553-557.

11. Heick H, égin-Heick N, Acharya C, Mohammed A. Automated determination of urine and cerebrospinal fluid proteins with Coomassie Brilliant Blue and the Abbott ABA-100. Clinical biochemistry. 1980;13(2):81-83.

12.Sax SM. Clinical Chemistry-Principles and Technics. R. J. Henry, J. W. Winkelman, D. C. Cannon, Eds. Harper \& Row Publishers. 2nd ed. New York. 1974, xii + 1629 pp. 267 illustrations. \$37.50. Clinical Chemistry. 1975;21(2):273-274.

13. Pesce MA, Strande CS. A new micromethod for determination of protein in cerebrospinal fluid and urine. Clinical chemistry. 1973;19(11):1265-1267. doi:10.1016/0026-265X(79)90037-7.

14. Swain RR, Briggs SL. Measurement of total protein in urine: Comparison of two dye-binding procedures with a gel filtration/ modified biuret method. Microchemical Journal. 1979;24(1):56-61. doi:10.1016/0026-265X(79)90037-7.

15. Macart M, Gerbaut L. An improvement of the Coomassie Blue dye binding method allowing an equal sensitivity to various proteins: application to cerebrospinal fluid. Clinica Chimica Acta. 1982;122(1):93-101.

16. Wimsatt DK, Lott JA. Improved measurement of urinary total protein (including light-chain proteins) with a Coomassie brilliant blue G-250sodium dodecyl sulfate reagent. Clinical chemistry. 1987;33(11):21002106.

17. Perini, J, Mizon C, Dehon B, Fialdes P, Lefebvre I, Mizon J, et al. Urinary protein determination using Coomassie Brilliant Blue in the presence of sodium dodecyi sulphate. Clinica chimica acta. 1984;143(3):321 328. doi:10.1016/0009-8981(84)90085-8.

18. Duhamel RC, Meezan E, Brendel K. The addition of SDS to the Bradford dye-binding protein assay, a modification with increased sensitivity to collagen. Journal of biochemical and biophysical methods. 1981; $5(2): 67-74$

19. López J, Imperial S, Valderrama R, Navarro S. An improved Bradford protein assay for collagen proteins. Clinica chimica acta 1993;220(1):91-100

20.Pande SV, Murthy MS. A modified micro-Bradford procedure for elimination of interference from sodium dodecyl sulfate, other detergents, and lipids. Analytical biochemistry. 1994;220(2):424-426.

21. Walker JM. The bicinchoninic acid (BCA) assay for protein quantitation in The Protein Protocols Handbook. 2009. Springer:11-15.

22. Alterman M, et al. AAARG2003 Study: Quantitation of proteins by amino acid analysis and colorimetric assays. Poster available for download from www. abrf. org (http://www. abrf. org/ResearchGroups/ AminoAcidAnalysis/EPosters/aaa2003_poster_print. pdf), 2003.

23. Keller RP, Neville MC. Determination of total protein in human milk: comparison of methods. Clinical chemistry. 1986;32(1):120-123.

24. Fountoulakis M, Juranville JF, Manneberg M. Comparison of the Coomassie brilliant blue, bicinchoninic acid and Lowry quantitation assays, using non-glycosylated and glycosylated proteins. Journal of biochemical and biophysical methods. 1992;24(3):265-274.

25. Walker J. Protein structure, purification, characterization and function analysis. Principles and techniques of Biochemistry and Molecular Biology. 2005:349-404
26. Katoch, Rajan. Analytical techniques in biochemistry and molecular biology. 2011:Springer Science \& Business Media.

27. Shivaraja Shankara YM, Ganesh MK, Shivashankara AR. Laboratory Manual for Practical Biochemistry. 2012: Jaypee Brothers, Medical Publishers.

28. Milio FR, Loffredo WM. Qualitative testing for amino acids and proteins. 1995: Chemical Education Resources.

29. Schegg KM, Denslow ND, Andersen TT, Bao Y, Cohen SA, Mahrenholz $\mathrm{AM}$, et al. Quantitation and identification of proteins by amino acid analysis: ABRF-96AAA collaborative trial. Techniques in Protein Chemistry. 1997;8:207-216.

30. Ramakrishnan S. Textbook of medical biochemistry. 2004: Orient Blackswan.

31. Corradini D. Handbook of HPLC. 2010: CRC Press.

32. Fountoulakis M, Lahm HW. Hydrolysis and amino acid composition analysis of proteins. Journal of Chromatography A. 1998;826(2):109134.

33. Reen DJ. Enzyme-linked immunosorbent assay (ELISA), in Basic Protein and Peptide Protocols. Springer. 1994;32:461-466.

34. Liddell J. Enzyme-linked Immunosorbent Assay (ELISA) to Measure Pure Protein. eLS. 2003. DOI: 10.1038/npg.els.0003764.

35. Topping MD, Forster HW, Dolman C, Luczynska CM, Bernard AM. Measurement of urinary retinol-binding protein by enzyme-linked immunosorbent assay, and its application to detection of tubular proteinuria. Clinical chemistry. 1986;32(10):1863-1866.

36. Lucertini S, Valcavi P, Mutti A, Franchini I. Enzyme-linked immunosorbent assay of retinol-binding protein in serum and urine. Clinical chemistry. 1984;30(1):149-151.

37. Dickinson J, Fowler SJ. Quantification of proteins on Western blots using ECL, in The Protein Protocols Handbook. Springer. 2002:429437.

38. Hossenlopp P, Seurin D, Segovia-Quinson B, Hardouin S, Binoux M. Analysis of serum insulin-like growth factor binding proteins using Western blotting: use of the method for titration of the binding proteins and competitive binding studies. Analytical biochemistry. 1986;154(1):138-143.

39. Rabilloud T, Lelong C. Two-dimensional gel electrophoresis in proteomics: a tutorial. Journal of Proteomics. 2011;74(10):18291841. doi: 10.1016/j.jprot.2011.05.040.

40. Nesvizhskii AI. Protein identification by tandem mass spectrometry and sequence database searching, in Mass Spectrometry Data Analysis in Proteomics. Springer. 2007;367:87-119. DOI:10.1385/1-59745275-0:87.

41. Mann M, Hendrickson RC, Pandey A. Analysis of proteins and proteomes by mass spectrometry. Annual review of biochemistry. 2001;70(1):437-473. DOI:10.1146/annurev.biochem.70.1.437.

42. Manabe T, Tachi K, Kojima K, Okuyama T. Two-dimensional electrophoresis of plasma proteins without denaturing agents. Journal of biochemistry. 1979;85(3):649-659.

43. Dale G, Latner A. Isoelectric focusing of serum proteins in acrylamide gels followed by electrophoresis. Clinica Chimica Acta. 1969;24(1):6168.

44. Chatterji B, Borlak J. A 2-DE MALDI-TOF study to identify disease regulated serum proteins in lung cancer of c-myc transgenic mice. Proteomics. 2009;9(4):1044-1056. doi:10.1002/pmic.200701135. 
45. Li X, Gong Y, Wang Y, Wu S, Cai Y, He P et al. Comparison of alternative analytical techniques for the characterisation of the human serum proteome in HUPO Plasma Proteome Project. Proteomics. 2005;5(13):3423-3441.

46. White S. Principles and techniques of biochemistry and molecular biology. Wiley Online Library. 2011;39(3).

47.SHORT A. Journal of Global Pharma Technology. 2009.

48. Sheehan D. Fast protein liquid chromatography (FPLC) methods, in Protein Purification Protocols. 1996;Springer:269-275.

49. Ly L, Wasinger VC. Protein and peptide fractionation, enrichment and depletion: tools for the complex proteome. Proteomics. 2011;11(4):513-534. doi: 10.1002/pmic.201000394.

50. Purcell A, Aguilar M, Hearn MT. Conformational effects in reversedphase high-performance liquid chromatography of polypeptides I. Resolution of insulin variants. Journal of Chromatography A. 1995; 711(1):61-70.

51.Wall DB, Kachman MT, Gong S, Hinderer R, Parus S, Misek DE, et al. Isoelectric focusing nonporous RP HPLC: a two-dimensional liquid-phase separation method for mapping of cellular proteins with identification using MALDI-TOF mass spectrometry. Analytical chemistry. 2000;72(6):1099-1111.

52. Nägele E, Vollmer M, Hörth P. Two-dimensional nano-liquid chromatography-mass spectrometry system for applications in proteomics. Journal of Chromatography A. 2003;1009(1):197-205.

53.Van Chi P, Dung NT. 2D-NanoLC-ESI-MS/MS for Separation and Identification of Mouse Brain Membrane Proteins. CHROMATOGRAPHY-THE MOST VERSATILE METHOD OF CHEMICAL ANALYSIS. 2012:63.

54. Choi KS, Song L, Park YM, Marshall J, Lund AL, Shion $\mathrm{H}$ et al.
Analysis of Human Plasma Proteome by 2DE-and 2D nanoLC-Based Mass Spectrometry. Preparative Biochemistry and Biotechnology. 2006;36(1):3-17. DOI:10.1080/10826060500388447.

55. Bauer A, Kuster B. Affinity purification-mass spectrometry. European Journal of Biochemistry. 2003;270(4):570-578. doi:10.1046/j.14321033.2003.03428.x.

56. Travis J, Pannell R. Selective removal of albumin from plasma by affinity chromatography. Clinica Chimica Acta. 1973;49(1):49-52.

57. Bécamel C, Galéotti N, Poncet J, Jouin P, Dumuis A, Bockaert J, et al. A proteomic approach based on peptide affinity chromatography, 2-dimensional electrophoresis and mass spectrometry to identify multiprotein complexes interacting with membrane-bound receptors. Biological procedures online. 2002;4(1):94-104. DOI:10.1251/bpo39.

58. Han D K, Eng J, Zhou H, Aebersold R. Quantitative profiling of differentiation-induced microsomal proteins using isotopecoded affinity tags and mass spectrometry. Nature biotechnology. 2001;19(10):946-951. DOI:10.1038/nbt1001-946.

59. Beattie J. Size-exclusion chromatography, in Protein Targeting Protocols. Springer. 1998;88:65-69.

60. Opiteck G J, Ramirez SM, Jorgenson JW, Moseley MA. Comprehensive two-dimensional high-performance liquid chromatography for the isolation of overexpressed proteins and proteome mapping. Analytical biochemistry. 1998;258(2):349-361.

61. Opiteck G J, Jorgenson J W, Anderegg R J. Two-dimensional SEC/RPLC coupled to mass spectrometry for the analysis of peptides. Analytical chemistry. 1997;69(13):2283-2291.

62. Owen W E, Roberts W L. Performance characteristics of an HPLC assay for urinary albumin. American journal of clinical pathology. 2005;124(2):219-225. DOI:10.1309/F6WV-K152-5KLQ-GXR4. 